\title{
Participation of the autonomic cardiac system in dogs with chronic myxomatous degeneration of the mitral valve
}

\author{
[Participação do sistema autonômico cardíaco em cães com degeneração \\ mixomatosa da válvula mitral] \\ R.A. Navarrete ${ }^{1}$, A.A. Camacho ${ }^{2}$ \\ ${ }^{1}$ Aluno de pós-graduação - Universidade Estadual Paulista - São Paulo, SP \\ ${ }^{2}$ Universidade Estadual Paulista - São Paulo, SP
}

\begin{abstract}
An exploratory multivariate analysis of factors of echocardiographic variables and those of the Holter test of $38 \mathrm{dogs}$ with MVMD staged in three classes (class 1a, class $1 \mathrm{~b}$, class 2) of congestive heart failure proposed by the ISACHC. The purpose of this analysis was learning the processes that would explain the behavior of the variables described, using exploratory multivariate techniques of factors. Five independent factors were determined (PNS to SF) which altogether explain $82.17 \%$ of the shared variance of the data. It was identified that among the five factors, the first process (PNS) is the first factor in importance, recruiting the highest percentage of variance $(37.96 \%)$ and represents the participation of the cardiac autonomic nervous system.
\end{abstract}

Keyword: endocardiosis, heart rate variability, factors, cardiac autonomic nervous system

\section{RESUMO}

Foi realizada análise multivariada exploratória de fatores das variáveis ecocardiográficas e do exame Holter de 38 cães com DMVM estadiados em três classes (classe 1a, classe 1b, classe 2) da insuficiência cardíaca congestiva proposta pela ISACHC. O objetivo desta análise foi conhecer os processos que explicariam o comportamento das variáveis descritas, utilizando-se para esse fim técnicas multivariadas exploratórias de fatores. Foram determinados cinco fatores independentes (PNS até SF) que, em conjunto, explicam $82,17 \%$ da variância compartilhada dos dados. O primeiro processo (PNS) é o primeiro fator em importância, recrutando a maior porcentagem da variância total $(37,96 \%) e$ representa a participação do sistema nervoso autônomo cardíaco.

Palavras-chave: endocardiose, variabilidade da frequência cardíaca, fatores

\section{INTRODUCTION}

Mitral valve myxomatous degeneration (MVMD) is the most common acquired heart disease in dogs. Its prevalence can reach from $14 \%$ to $40 \%$ in small dogs, depending on the breed, and even achieve higher values in geriatric dogs. MVMD causes thickening and incomplete apposition of the valve layers during systole with secondary mitral regurgitation (Chetboul and Tissier, 2012). Thus, decreased cardiac efficiency occurs, resulting in a drop in blood pressure by activating compensatory mechanisms
(Masso, 1984; Guyton, 1986) as the renin angiotensin aldosterone system (RAAS) and the sympathetic nervous system (Snyder, 1991; Knight, 1992). Initially, these compensatory mechanisms cause tachycardia, peripheral vasoconstriction, with sodium and water retention, raising blood pressure and cardiac output, favoring tissue perfusion (Awan and Mason, 1996; Camacho, 1996). 
An enlarged atrium can trigger cardiac arrhythmias, including atrial and junctional ones (Brundel et al., 2005). In such cases, premature supraventricular complexes and supraventricular tachycardia are most commonly diagnosed. On the other hand, atrial fibrillation, even being the most commonly arrhythmia associated with a dilated left atrium, has low incidence in MVMD (Guglielmini et al., 2000).

For a definitive diagnosis of MVMD, an echocardiogram is indicated, to accurately and anatomically determine changes present in valve disease (Muzzi et al., 1999). An echocardiographic examination evaluates the characteristics of the left ventricular volume overload, including the increased diastolic volume and the increased septal hyperkinesia demonstrated by an increase in the shortening fraction value (FS\%) (Kienle and Thomas, 2004). In general, changes are related to volume overload, with a gradual increase in the left atrial pressure and elongation of the left atrium (Kittleson, 2006).

Holter is the most comprehensive method to evaluate heart rate, providing qualitative and quantitative information on normal complexes, heart rate, cardiac arrhythmias, heart rate variability determination, among others (Nogueira and Cavalcanti 2007). The cardiac autonomic nervous system of healthy patients is predominantly influenced by the parasympathetic tone, resulting in a greater HRV. However, heart diseases, especially when heart failure occurs, generate an increased sympathetic tone and a decreased parasympathetic tone, resulting in heart rate rise and HRV drop (Oliveira et al., 2012). During the CHF initial phase, even before the emergence of any signs, the heart autonomic control is changed already, due to an increased sympathetic tone and a decreased parasympathetic tone. This way, the correct evaluation of HRV changes is an important factor to be considered to diagnose heart failure early (Heart..., 1996). In general, the indexes analyzing the HRV (NNm, SDNN, SDANN, SDNNid, rMSSD, $\mathrm{PNN}>50 \%$ ) are related in different degrees and indicate greater participation of the parasympathetic nervous system in relation to the sympathetic nervous system when they increase and lower participation of parasympathetic autonomic nervous system when they decrease (Ravenswaaij-Arts et al., 1993).

The purpose of this analysis was learning the processes that would explain the behavior of the variables of the echocardiographic examination and the Holter test in dogs with MVMD in the different stages of congestive heart failure, using multivariate exploratory techniques of factors.

\section{MATERIAL AND METHODS}

The experiment was conducted at the Veterinary Hospital of FCAV- UNESP, São Paulo, Brazil, and dogs were examined by the Veterinary Cardiology service. For this study, 38 dogs with mitral valve myxomatous degeneration (MVMD), of different breeds, male and female, small-to-medium sized, aged between 6 and 16 years-old, were used. These 38 dogs with MVMD were selected into three groups per degree of congestive heart failure (CHF) proposed by the International Small Animal Cardiac Hearth Council (ISACHC) (Fox et al., 1999). To be classified by CHF stage, the dogs were evaluated based upon their physical and echocardiographic exams. Class 1a was comprised by 13 dogs with an average weight of $13.2 \mathrm{~kg}(6.0-22.2 \mathrm{~kg})$. Class $1 \mathrm{~b}$ consisted of 10 dogs, with an average weight of $6.4 \mathrm{~kg}$ (4.4$10.6 \mathrm{~kg}$ ), while those of class 2 were comprised by 15 dogs, with an average weight of $8.6 \mathrm{~kg}$ $(2.7-20.9 \mathrm{~kg})$. This research was approved by the Ethics Committee on the use of animals, Protocol No. 022142/12, adopted by Brazilian College of Animal Experimentation (COBEA).

The physical examination was used to classify the animals during the CHF staging, as well as serving as a discriminating examination and a method of eliminating another comorbidity. Medication adjustments in dogs so requiring for the CHF stage were performed by guidelines for the diagnosis and treatment of Canine Chronic Valvular Heart Disease (Atkins et al., 2009). After this adjustment, the dog was incorporated in this study.

The echocardiographic examination was also used to stage the CHF degree. Echocardiography was performed with the aid of an echocardiograph (300S Pandion Vet-Pie Medical (B) equipped with a multi-frequency transducer (3.5-10MHz). The dogs from each group were 
positioned in lateral decubitus, using the right parasternal window and the left parasternal window for the echocardiographic evaluation (Boom 2011). The echocardiographic variables used in the analysis were the left atrium relation indexed by the inner diameter of the aorta artery (LA/Ao), the left atrium-aorta cross-section, the interventricular septum thickness (IVS), the left ventricular inner dimension (LVD), the left ventricle free wall thickness (PW), calculated measures in systole (s) and diastole (d), papillary cross-section and $\mathrm{M}$ mode. The measurements previously determined were indexed by the inner diameter of the aorta (Ao), neutralizing the effect of the weight of the dogs on the measurements of the heart chambers (Boon, 2011). The ejection fraction $(\mathrm{EF} \%)$ and the left ventricular shortening fraction (FS\%) were calculated using the Teicholz method. After a four-chamber apical cross-section, the maximum speed of the transmittal flow, determining the maximum speed of the E wave (E), the maximum speed of A wave (A) and the E/A relation were evaluated.

For the Holter test, electrodes were connected to the animal skin, in the thoracic region, according to the Cardios manual and Spier and Meurs (2004). The evaluation was performed by the Veterinary Hospital, providing food, bedding, medicines and particular implements to each patient during the 24 hours of the recording. Tests were analyzed by the same observer. Normal, supraventricular and ventricular morphology were corrected, artifacts were excluded, and the electrocardiographic record waves were renamed in case of incorrect determination by Cardios (CardioSmart ${ }^{\circledR}$ version 5.0 Professional CS 540). This analysis is critical to obtaining a reliable record on the canine species. Holter test variables were mean heart rate $(\mathrm{HRm})$, number of ECG complexes $\left(\mathrm{N}^{\circ} \mathrm{QRS}\right)$, period in hours of a heart rate above
160 beats per minute $(\mathrm{bpm})(\mathrm{H}>160)$, time in hours of heart rate below $60 \mathrm{bpm}(\mathrm{H}<60)$, number of supraventricular arrhythmias ( $\left.{ }^{\circ} \mathrm{SVA}\right)$, number of ventricular arrhythmias $\left(\mathrm{N}^{\circ} \mathrm{VA}\right)$. The variables analyzing the heart rate variability (HRV) were: average of all normal RR intervals of the examination (NNm), standard deviation of all normal RR intervals of the examination (SDNN), average of the standard deviations calculated for normal RR intervals taken every five minutes (SDNNid) and percentage of differences greater than 50 milliseconds between adjacent normal RR intervals ( $\mathrm{PNN}>50 \%$ ).

The statistical analysis was performed based on the exploratory multivariate analysis of factors to determine the processes that would explain the data total variance. For this analysis, data from the Holter test and echocardiographic examination was used. Data was previously standardized and considered eigenvalues greater than one $(>1)$ according to the Kaiser criterion for obtaining the number of factors. For rotation of factors, the Varimax method was used, and loads of factors greater than 0.5 were considered (Hair et al., 2009). The multivariate analysis was obtained using the Statistica 7 program.

\section{RESULTS}

Five eigenvalues on the exploratory analysis of factors extracted by the main components method were considered. Admitting the Kaiser criterion which considers eigenvalues greater than one $(>1)$, the number of factors to be adopted were five. The eigenvalue of the first factor is 8.35 , which is an expressive value, since the sum of all eigenvalues is 22 (total variance equals 22). The variance proportion retained by the eigenvalue of the first factor is approximately $37.96 \%$. In Table 1, eigenvalues 2, 3, 4 and 5, as well as their respective variances can be seen.

Table 1. Eigenvalues, variance and cumulative variance determined by exploratory analysis of factors according to the Kaiser criterion in dogs with CHF by MVMD

\begin{tabular}{ccccc}
\hline Factors & Interpretation & Eigenvalue & Variance $(\%)$ & Cumulative Variance $(\%)$ \\
\hline 1 & PNS & 8.35 & 37.96 & 37.96 \\
2 & SLV & 4.88 & 22.19 & 60.15 \\
3 & MF & 2.44 & 11.09 & 71.24 \\
4 & SVA & 1.37 & 6.24 & 77.48 \\
5 & SF & 1.03 & 4.69 & 82.17 \\
\hline
\end{tabular}


The five factors could retain altogether $82.17 \%$ of the shared total variance. The first factor (PNS) recruits $37.96 \%$ of the data total variance and represents the most important factor of the five factors. PNS has eight variables of the Holter test (HRm, $\mathrm{N}^{\circ} \mathrm{QRS}, \mathrm{H}>160, \mathrm{NNm}$, SDNN, SDNNid, PNN>50\%, $\mathrm{H}<60$ ). The SLV has $22.19 \%$ of the total variance of data and represents the second factor in importance, comprised by the morphology variables of the left ventricle determined in a papillary crosssection echocardiography indexed by the aorta inner diameter (IVSd/Ao, IVSs/Ao, LVDs/Ao, LVDd/Ao, PWs/Ao). The MF has $11.09 \%$ of the total variance of data and represents the third factor in importance in the analysis and is comprised by the mitral flow variables and the number of ventricular arrhythmias (E, A, E/A relation, $\mathrm{N}^{\circ} \mathrm{VA}$ ). The SVA has $4.69 \%$ of the total variance of data and represents the fourth factor in importance, being comprised by LA/Ao relation and the number of supraventricular arrhythmias ( ${ }^{\circ} \mathrm{SVA}$ ). The SF has $6.24 \%$ of the data total variance, comprised by the systolic function and the left ventricular free wall thickening (EF\%, FS\%, PWd/Ao) variables (Table 2 and Figure 1).

Table 2. Representation of five factors determined by the exploratory analysis of factors in dogs with CHF by MVMD

\begin{tabular}{|c|c|c|c|c|c|}
\hline Variables & PNS & SLV & MF & SVA & SF \\
\hline $\mathrm{HRm}$ & 0.98 & 0.05 & 0.00 & 0.00 & 0.04 \\
\hline $\mathrm{N}^{\circ} \mathrm{QRS}$ & 0.97 & 0.06 & 0.01 & 0.01 & 0.07 \\
\hline $\mathrm{H}>160$ & 0.81 & 0.11 & -0.06 & -0.11 & 0.08 \\
\hline $\mathrm{NNm}$ & -0.97 & -0.10 & -0.02 & -0.05 & -0.01 \\
\hline SDNN & -0.91 & -0.05 & -0.04 & -0.12 & 0.03 \\
\hline SDNNid & -0.88 & -0.04 & 0.00 & -0.10 & -0.03 \\
\hline $\mathrm{PNN}>50 \%$ & -0.89 & -0.10 & 0.06 & -0.03 & -0.02 \\
\hline $\mathrm{H}<60$ & -0.78 & -0.20 & -0.07 & -0.26 & 0.05 \\
\hline IVSd/Ao & 0.10 & 0.89 & -0.02 & 0.01 & 0.19 \\
\hline IVSs/Ao & 0.06 & 0.86 & 0.16 & 0.10 & 0.36 \\
\hline LVDs/Ao & 0.21 & 0.70 & -0.10 & 0.50 & 0.18 \\
\hline LVDd/Ao & 0.17 & 0.68 & -0.03 & 0.50 & 0.34 \\
\hline PWs/Ao & 0.11 & 0.68 & -0.04 & 0.11 & 0.57 \\
\hline $\mathrm{E}$ & 0.26 & 0.03 & 0.81 & 0.13 & 0.32 \\
\hline $\mathrm{E} / \mathrm{A}$ & -0.10 & -0.53 & 0.69 & 0.26 & -0.17 \\
\hline A & 0.22 & 0.39 & 0.67 & -0.19 & 0.37 \\
\hline $\mathrm{N}^{\circ} \mathrm{VA}$ & 0.31 & -0.02 & -0.83 & 0.21 & 0.16 \\
\hline $\mathrm{N}^{\circ} \mathrm{SVA}$ & -0.05 & 0.16 & 0.04 & 0.73 & -0.06 \\
\hline LA/Ao & 0.33 & 0.31 & -0.11 & 0.62 & 0.49 \\
\hline FS\% & -0.04 & 0.30 & 0.08 & 0.06 & 0.92 \\
\hline FE\% & -0.05 & 0.31 & 0.04 & 0.03 & 0.90 \\
\hline PWd/Ao & 0.15 & 0.29 & 0.19 & 0.31 & 0.52 \\
\hline Variance $(\%)$ & 37.96 & 22.19 & 11.09 & 6.24 & 4.69 \\
\hline Interpretation & $\begin{array}{l}\text { Participation of the } \\
\text { autonomic nervous } \\
\text { system }\end{array}$ & $\begin{array}{c}\text { Size left } \\
\text { ventricular } \\
\text { (septum. } \\
\text { chamber. wall) }\end{array}$ & $\begin{array}{c}\text { Mitral flow } \\
\text { velocity }\end{array}$ & $\begin{array}{l}\text { Supraventricular } \\
\text { arrhythmias with left } \\
\text { atrial enlargement }\end{array}$ & $\begin{array}{l}\text { Systolic } \\
\text { function }\end{array}$ \\
\hline
\end{tabular}

Load and correlation $(+,-)$ of each variable with the factor greater than 0.5 were considered. Coefficients of the factor in black were used for interpretation and represent the greatest correlation value related to the factor. 


\section{DISCUSSION}

These five factors represent five processes, which would explain the distribution of the data total variance. These processes can guide the understanding of the differences among dogs in class $1 \mathrm{a}$, class $1 \mathrm{~b}$ and class 2 stages of $\mathrm{CHF}$ due to MVMD. For better understanding the analysis of the processes, each factor was named and interpreted by the characteristics of the variables included in the factor (Figure 1).

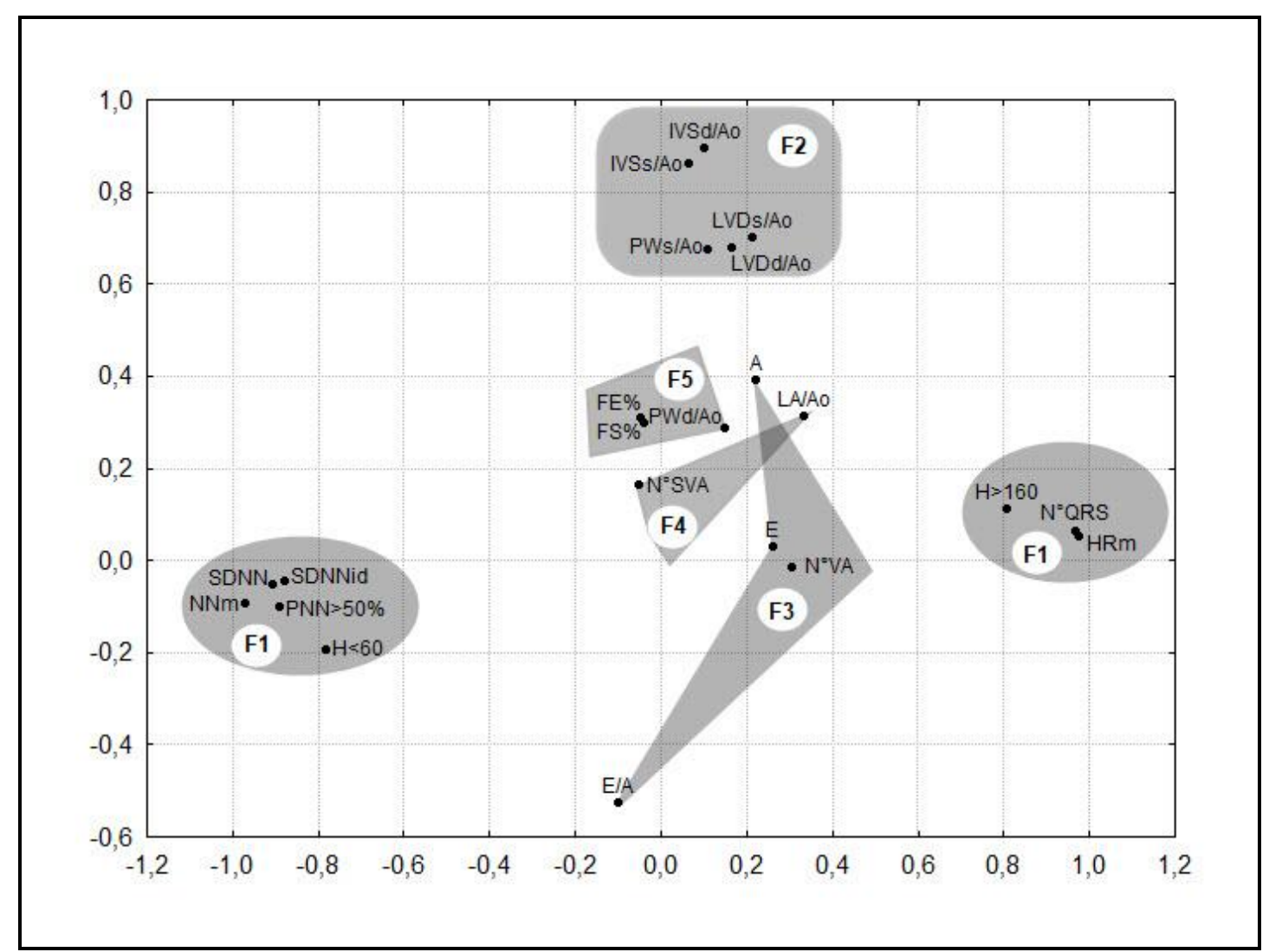

Figure 1. Spatial distribution of factors plotted with the loads of the variables for factor.

Factor 1: PNS, Factor 2: SLV, Factor 3: MF, Factor 4: SVA and Factor 5: SF.

The first factor (PNS) includes three variables with a positive correlation $\left(\mathrm{HRm}, \mathrm{N}^{\circ} \mathrm{QRS}\right.$, $\mathrm{H}>160$ ) and five variables with a negative correlation with respect to the factor $(\mathrm{NNm}$, SDNN, SDNNid, PNN $>50 \%, \quad \mathrm{H}<60)$. This correlation that when the average heart rate (HRm) increases, the number of QRS and the time with a heart rate greater than $160 \mathrm{bpm}$ $(\mathrm{H}>160)$ are subsequently increased. This increase may be related to the activation of the sympathetic autonomic nervous system which causes tachycardia and peripheral vasoconstriction, as well as is confirmed by a study performed in dogs with CHF subclinical (class 1a, class 1b) and clinical (class 2 and class 3 ) in MVMD, which determined an increase in the average heart rate of dogs with a clinical
CHF, when compared to the group with a subclinical CHF (Crosara et al., 2010).

In contrast, the five variables with a negative correlation (NNm, SDNN, SDNNid, PNN $>50 \%$, $\mathrm{H}<60)$ decrease when the HRm increases. When these five variables decrease, they are related to a decrease in the heart rate variability (HRV) in dogs with CHF, representing a lower participation of the parasympathetic autonomic nervous system. It is suggested that the attenuation of the parasympathetic nervous system and the activation of the sympathetic nervous system can be the first determining factors in $\mathrm{CHF}$ in dogs with MVMD. Lower pNN50\% and SDANN values indicate a decrease in the parasympathetic activity and a reduced 
HRV, being associated with the CHF syndrome in dogs with MVMD (Oliveira et al., 2012). The PNS is the first and most important factor, representing the highest percentage of the variance explained. Considering the variables included in PNS, it was interpreted as the effective participation of the sympathetic and parasympathetic autonomic nervous system.

The SLV included five variables with a positive correlation (IVSd/Ao, IVSs/Ao, LVDs/Ao, LVDd/Ao, PWs/Ao), indicating that the increased thickening of the interventricular septum also increases the ventricular chamber (in systole and in diastole). This second process corresponds to the size of the left ventricle (septum, chamber, and wall), which, due to an increase in the preload and because of the activation of the renin angiotensin aldosterone system increases during the MVMD progression. A study showing this same behavior was developed by Franco et al. (2011), determining that the thickening of the interventricular septum and the left ventricular chamber in systole and diastole (IVSd, IVSs, LVDd, LVDs,) have different values among the functional classes of CHF in dogs with MVMD, and can be used as prognostic factors and to evaluate the effectiveness of therapeutic protocols for the CHF treatment.

The MF included three variables with a positive correlation $(\mathrm{E}, \mathrm{A}, \mathrm{E} / \mathrm{A})$, which were the mitral flow waves and a variable with a negative correlation which corresponded to the number of ventricular arrhythmias $\left(\mathrm{N}^{\circ} \mathrm{VA}\right)$. This relation indicates that increasing the speed of the mitral $\mathrm{E}$ wave increases the speed of the A wave and the relation of both speeds of the mitral flow. Therefore, it was observed that an increased mitral flow ( $\mathrm{E}$ and $\mathrm{A}$ ) has an inverse relation with the number of ventricular arrhythmias. There is a maximum speed increase of the mitral flow (E and A), when dogs with MVMD develop CHF. An increase in the maximum speed of the mitral $\mathrm{E}$ wave, during the echocardiographic serial study, indicates progression of the disease in question and can identify dogs with a higher risk of death from congestive heart failure (Hezzell et al., 2012). Considering that ventricular arrhythmias occur at the beginning of the mitral disease (Navarrete, 2013) and the mitral flow increases with the disease progression by increased pressure in the left atrium, ventricular arrhythmias could be explained to occur with the mitral flow at a lower or normal speed and there would be, therefore, a negative correlation within MF. Therefore, the third process must be interpreted in the light of the mitral flow speed.

In its turn, the SVA includes two variables with a positive correlation, the number of supraventricular arrhythmias ( $\left.\mathrm{N}^{\circ} \mathrm{SVA}\right)$ and the left atrium/aorta relation (LA/Ao). This correlation indicates that when the number of supraventricular arrhythmias increases, the same happens with LA/Ao. This positive correlation included in SVA could be an answer to the proposed hypothesis, that a larger number of supraventricular arrhythmias determined in dogs with an increased left atrium should correlate with the left atrial increase and that dogs with LA/Ao relation $>1.7$ had more supraventricular arrhythmias (Crosara et al., 2010). Therefore, SVA relates supraventricular arrhythmias to the left atrial increase.

Finally, the SF includes three variables with a positive correlation (EF\% FS\%, PWd/Ao). This factor relates two variables of the systolic function of the left ventricle (ejection fraction and shortening fraction) to a variable of the left ventricular free wall thickening (PWd/Ao). It can be concluded that the FS\% of dogs with MVMD increases to the extent that CHF develops, an effect probably generated by an increased left ventricular distension (due to an increased preload) and a larger contraction following this distension (Frank-Starling mechanism). Dogs with a slight degree of mitral valve regurgitation have an average value of $37 \%$, with a moderate degree values of $40 \%$, and with a severe degree values of $51 \%$ (Kittleson, 2006). Such increases were determined the same way in the papers of Muzzi et al. (1999) and Kienle and Thomas (2004). Progression of canine MVMD is mainly characterized by the hyperdynamic state of the left ventricle with an increased $\mathrm{EF} \%$ and $\mathrm{FS} \%$ due to the combination of the volume overload (i.e., left ventricular diastolic dilatation), increased afterload and increased sympathetic tone (Chetboul and Tissier, 2012). For that reason, both variables have a direct distribution. Therefore, the SF has a direct relation with the left ventricular systolic function. 


\section{CONCLUSION}

The five processes explaining altogether $82.17 \%$ of the total variance of the Holter test and echocardiography examinations in dogs with MVMD in CHF classes were determined by the exploratory analysis of factors. Based upon this investigation, it has been identified that the first process (PNS) is the first factor in importance, recruiting the highest percentage of the shared variance and represents the participation of the cardiac autonomic nervous system.

\section{REFERENCES}

ATKINS, C.; BONAGURA, J.; ETTINGER, S. et al. Guidelines for the diagnosis and treatment of canine chronic valvular heart disease. J. Vet. Intern. Med., v.23, p.1142-1150, 2009.

AWAN, N.A.; MASON D.T. Direct selective blockage of the vascular angiotensin 2 receptors in therapy for hypertension and severe congestive heart failure. Am. Heart J., v.131, p.177-185, 1996.

BOON, J.A. Manual of veterinary echocardiography. 2.ed. [Hoboken]: WileyBlackwell, 2011. p.248.

BRUNDEL, B.J.J.M.; MELNYK, P.; RIVARD, L.; NATTEL, S. The pathology of atrial fibrillation in dogs. J. Vet. Cardiol., v.7, p.121129, 2005.

CAMACHO, A.A. Estudo clínico, caracterização morfométrica e quantitativa dos neurônios ganglionares atriais da faixa intercaval de cães com miocardiopatia dilatada congestiva idiopática. 1996. 56f. Tese (Livre Docência) Faculdade de Ciências Agrárias e Veterinárias, Universidade Estadual Paulista, Jaboticabal, SP.

CHETBOUL, V.; TISSIER, R. Echocardiographic assessment of canine degenerative mitral valve disease. J. Vet. Cardiol., v.14, p.127-148, 2012.

CROSARA, S.; BORGARELLI, M.; PEREGO, M. et al. Holter monitoring in 36 dogs with myxomatous mitral valve disease. Aust. Vet. J., v.88, p.386-302, 2010.

FOX, P.R.; SISSON, D.; MOÏSE, N.S. Recommendations for diagnosis of heart disease and treatment of heart failure in small animals. Philadelphia: W.B. Saunders, 1999. (Appendix A.)
FRANCO, R.; CHAMPION, T.; PASCON, J. et al. Utilização do maleato de enalapril, furosemida, espironolactona e suas associações em cães com doença degenerativa mixomatosa da válvula mitral. Ars Vet., v.27, p.85-93, 2011.

GUGLIELMINI, C.; CHETBOUL, V.; PIETRA, M. et al. Influence of left atrial enlargement and body weight on the development of atrial fibrillation: retrospective study on 205 dogs. Vet. J., v.160, p.235-241, 2000.

GUYTON, A.C. Regulación de la presión arterial: regulación rápida de la presión mediante reflejos nerviosos y otros mecanismos. In: Tratado de fisiología médica. [São Paulo]: Interamericana-Mc Graw Hill, 1986. p.244-55.

HAIR, J.F.; BLACK, W.C.; BABIN, B.J.; ANDERSON R.E. Análise factorial. In: HAIR, J.F. et. al. Análise multivariada de dados. 6.ed. Porto Alegre: Bookman, 2009. p.100-146.

HEART rate variability: standards of measurements, physiological interpretation and clinical use. Task Force of the European Society of Cardiology and the North American Society of Pacing and Electrophysiology. Circulation, v.93, p.1043-1065, 1996.

HEZZELL, M.J.; BOSWOOD, A.; MOONARMART, W.; ELLIOTT, J. Selected echocardiographic variables change more rapidly in dogs that die from myxomatous mitral valve disease. J. Vet. Cardiol., v.14, p.269-279, 2012.

KIENLE, R.D. THOMAS W.P. Ecocardiografia. In: NYLAND, T.G.; MATTOON, J.S. Ultra-som diagnóstico em pequenos animais. 2.ed. São Paulo: Roca, 2004. p.368-438.

KITTLESON, M.D. Myxomatous atrioventricular valvular degeneration. In: Textbook of cardiovascular medicine. 3.ed. St. Louis: Mosby DVD, 2006. p.52.

KNIGHT, D.H. Fisiopatologia da insuficiência cardíaca. In: ETTINGER, S.J. Tratado de medicina interna veterinária. São Paulo: Manole, 1992. p.944-969.

MASSO, D.T. Regulación de la función del corazón en la enfermedad cardiaca crónica. In: _. Insuficiencia cardiaca congestiva. Mecanismos, evaluación y tratamiento. Barcelona: Doyma, 1984. p.100-116. 
MUZZI, R.A.L.; MUZZI, L.A.L.; ARAUJO, R.B. et al. Diagnostico ecodopplercardiográfico na fibrose crônica da valva mitral em cão. Arq. Bras. Med. Vet. Zootec., v.51, p.1-6, 1999.

NAVARRETE, R.A. Variabilidade $d a$ frequência cardíaca em cães com degeneração mixomatosa crônica da valva mitral. 2013. 70f. Dissertação (Mestrado em Medicina Veterinária) - Faculdade de Ciências Agrárias e Veterinárias, Universidade Estadual Paulista, Jaboticabal, SP.

NOGUEIRA, R.B.; CAVALCANTI, G.A.O. Eletrocardiografia contínua (Holter). In: MUZZI, R.A.L.; NOGUEIRA, R.B. (Eds.). Cardiologia: métodos diagnósticos das afecções cardiovasculares em pequenos animais. Lavras: UFLA/FAEPE, 2007. p.70-78.
OLIVEIRA, M.S.; MUZZI, R.A.; ARAÚJO, R.B. et al. Heart rate variability parameters of myxomatous mitral valve disease in dogs with and without heart failure obtained using 24-hour Holter electrocardiography. Vet. Rec., v.170, p.622, 2012.

RAVENSWAAIJ-ARTS, C.M.A.V.; KOLLEE, L.A.A.; HOPMAN, J.C.W. et al. Heart rate variability. Ann. Intern. Med., v.118, p.436-447, 1993.

SNYDER, P.S. Canine hipertensive disease. Comp. Educ. Neview, v.13, p.1785-1792, 1991.

SPIER, A.W.; MEURS, K.M. Assessment of heart rate variability in Boxers with arrhythmogenic right ventricular cardiomyopathy. J. Am. Vet. Med. Assoc., v.224, p.534-537, 2004. 